\title{
Safety Leadership as a Means for Safe and Sustainable Shipping
}

\author{
Nermin Hasanspahić ${ }^{1, *} \mathbb{1}$, Vlado Frančić ${ }^{2}$, Srđan Vujičić ${ }^{1}\left(\mathbb{D}\right.$ and Mario Mandušić ${ }^{3}$ \\ 1 Maritime Department, University of Dubrovnik, 20000 Dubrovnik, Croatia; srdjan.vujicic@unidu.hr \\ 2 Faculty of Maritime Studies, University of Rijeka, 51000 Rijeka, Croatia; vfrancic@pfri.hr \\ 3 Independent Researcher, 20000 Dubrovnik, Croatia; mario.mandusic1729@gmail.com \\ * Correspondence: nermin.hasanspahic@unidu.hr
}

Citation: Hasanspahić, N.; Frančić

V.; Vujičić, S.; Mandušić, M. Safety

Leadership as a Means for Safe and Sustainable Shipping. Sustainability 2021, 13, 7841. https://doi.org/ $10.3390 /$ su13147841

Academic Editors: Virginia Bodolica and Martin Spraggon

Received: 16 June 2021

Accepted: 10 July 2021

Published: 13 July 2021

Publisher's Note: MDPI stays neutral with regard to jurisdictional claims in published maps and institutional affiliations.

Copyright: (C) 2021 by the authors Licensee MDPI, Basel, Switzerland. This article is an open access article distributed under the terms and conditions of the Creative Commons Attribution (CC BY) license (https:/ / creativecommons.org/licenses/by/ $4.0 /)$.

\begin{abstract}
Safety leadership is critical in high-risk industries such as shipping since inadequate leadership can cause marine accidents, resulting in injuries, fatalities, damage to property and environmental pollution. One of the aspects of good and effective safety leadership is creating good human relations and satisfaction among crewmembers, considered a precondition for effective teamwork. Officers on board ships should establish effective teamwork and implement adequate safety leadership, positively affecting safety culture, increasing safety in general and improving marine environment protection. Safety leadership onboard ships comprises several characteristics, including maintaining safe work performance, carrying out safety training, and encouraging crewmember morale. Therefore, it is essential for all stakeholders in shipping industries that officers onboard ships can identify those characteristics, adapt, and apply them adequately. This paper presents the characteristics and skills that shipboard officers need to apply in order to be excellent leaders and serve with adequate safety leadership abilities. One tool for recognizing those characteristics and skills was a survey carried out among experienced professional seafarers. Analysis of the survey data revealed latent factors, these being transformational and transactional leadership elements affecting safety leadership onboard ships.
\end{abstract}

Keywords: safety leadership; safety; environmental protection; shipping; teamwork

\section{Introduction}

Seafaring is a unique occupation, involving long periods of staying away from family and working in a harsh environment. Besides the social distancing from family and friends, and living and working onboard a ship with a closed group of people, seafarers are exposed to various hazards during their daily work $[1,2]$. To cope with all those challenges, seafarers need to be well prepared, educated and trained. Work onboard ships is usually carried out in teams; thus, seafarers need to be proficient in the ship's official language to be able to communicate with others. There are several departments within a ship; for example, there are deck, engine, and galley departments on a merchant cargo ship. Within these departments, seafarers are divided into teams that perform daily work [3]. To be effective and safe, each team has a leader, who is usually the highest-ranking officer among the team members [4]. It is assumed that the leader is the most experienced and the most competent member within a team. The master is the leader of all shipboard teams. Because people's safety is the number one priority, all shipboard teams need to function appropriately and cooperate to perform all tasks safely and effectively [4]. A competent team leader should enable safe and effective work performance, and a master as a shipboard leader should monitor all teams' performance onboard a ship, and take responsibility for their actions and safety $[4,5]$.

Safety in shipping is primarily affected by the human factor, because human error is accounted as the cause of about $80 \%$ of marine accidents [6]. Human error can be defined as "a deviation from expected human performance, where the person that arbitrates did 
the error occurred has to have criterion what is and what is not an error. This distinction concerns whether human behavior alone is examined or the performance of the humanmachine system as a whole" [7]. In other words, the seafarer has to understand how to perform their duties to carry out any given job safely and efficiently. Someone has to explain them to the seafarer, and that should be the team leader. Poor leadership skills, inadequate task-related information, and poor communication commonly lead to human error-making and accidents [4]. Since new technologies are introduced in shipping, and human-machine interaction is needed, we are currently witnessing a number of technologyinduced human errors [8]. However, smart technologies might be one of the factors that might reduce human error and improve human performance. Augmented reality might enable the real-time training of the operator, thus helping to minimize human errors due to the incorrect execution of one of the elementary tasks [9]. Human reliability within complex socio-technical systems depends on several influencing factors that describe the necessary prerequisites for errors. These are performance-shaping factors (PSF), and they might be divided into the following categories: external factors, internal factors and stress factors. Leadership behavior can be included in internal factors because it affects human motivation and behavior [10].

With teamwork and resource management, shipboard leadership has often been recognized as a frailty onboard ships during emergencies. There are numerous examples of marine accidents due to poor shipboard leadership practice. One example of such an accident is the motor tanker Ovit's grounding, which happened due to the ship's master's ineffective onboard management and poor leadership. A safety culture could not be developed and instilled on board because of poor leadership practice [11]. Another example is the fire on the motor vessel Celtic Carrier, which occurred because senior officers did not provide the necessary leadership, especially during firefighting efforts. Their poor leadership resulted in the shipboard firefighting team's bewilderment [12]. A well-known example of poor leadership practice, which led to 32 fatalities (two persons still missing) [13] and causing marine pollution (microplastics) after wreck removal [14], was the capsizing of the cruise ship Costa Concordia. The poor leadership that the master exhibited affected the safety culture onboard the ship, resulting in the bridge team's substandard performance and routine violations of rules and regulations $[13,15,16]$. A rather recent example of a disastrous effect on the marine environment was the grounding of the motor vessel Wakashio, which caused a large oil spill off the coast of Mauritius. The formal accident investigation is not yet completed, but the company's internal post-accident investigation revealed complacency and lack of situational awareness as contributing factors, along with inadequate safety culture onboard the ship [17]. These contributing factors might have been successfully mitigated if there had been effective safety leadership instilled onboard each vessel.

The International Maritime Organization (IMO) introduced mandatory competence standards for leadership, human relations, and teamwork skills at the management and operational level, to prevent poor leadership and inadequate human relations. Competence standards for the certification of watchkeeping officers and engineers are regulated by the International Convention on Standards of Training, Certification and Watchkeeping for Seafarers (STCW) 1978, as amended [18]. Following STCW requirements, the IMO introduced model courses to support training providers in developing leadership training programs and adequately dealing with the subject. Besides the STCW convention, leadership and teamwork are among the topics of other non-mandatory tailored training requirements introduced by some shipping companies. Shipboard team leaders (senior and junior officers) attend shore-based courses to prepare themselves for effective leadership and human relations. Nevertheless, without good leadership onboard ships, all these instruments are inefficient, and thus the ships' masters should verify that compliance on all levels is achieved [2].

Although it can be expected that crewmembers are mostly well trained and educated, and their leaders appreciate safety as the number one priority, accidents that have human 
factors as one of the root causes still happen. Because inadequate leadership is closely connected with poor human relations and teamwork, and is one of the causes of human error onboard ships, further research is needed on this topic. To adequately address that issue, it is necessary to explain the terms "leadership" and "safety leadership". The IMO defines leadership as "a process where one group of individuals influenced by an individual tries to achieve a common goal" [19]. Wu [20] defined safety leadership as "the process of interaction between leaders and followers, through which leaders can exert their influence on followers to achieve organizational safety goals under the circumstances of organizational and individual factors." It can be concluded that without the subordinates' support, it is impossible to be a successful leader and effectively implement safety-oriented culture onboard a ship. Therefore, safety leadership is considered a part of effective leadership, and it focuses on the leadership aspects of minimizing risks and accident prevention, i.e., the safety aspects [21].

Because safety leadership is of great importance in high-risk industries, researchers have identified its characteristics and ways to achieve it. As the seafaring profession includes a dangerous environment, and professional relations onboard a ship incorporate a steep hierarchy, it is crucial to implement safety leadership to prevent accidents and improve safety. Several studies have researched the area of safety leadership in shipping. $\mathrm{Lu}$ and Yang [22] researched container terminal workers, and identified three main safety leadership dimensions: safety motivation, safety policy, and safety concern. Bhattacharya and Tang [23] examined the difficulties of employee participation in occupational safety and health (OSH) management onboard ships. They found that the main barriers are fear of losing employment and a steep shipboard hierarchy; thus, employees' participation depends on senior officers' ability to apply appropriate leadership styles. Hanzu-Pazara et al. [6] argued that teamwork and leadership are essential parts of a human factor and considered a tool for implementing safety policies onboard ships. Bielić et al. [3] described the efficiency of decision-making within a shipboard team by introducing teamwork. The authors introduced a participation-based model of ship crew management as an optimum for safe and efficient teamwork. Research done by Theotokas et al. [5] focused on the leadership profiles of ocean-going ship masters. In their research, respondents emphasized the importance of a team and crewmembers' motivation as a factor crucial for leadership success. The ship masters' opinion is that leaders are created through experiences and situations, and their efficacy depends on their relationships with subordinates. Intensive workload, poor understanding of the equipment, a steep authority gradient, lack of collaboration, poor communication, and crewing strategies are considered as contributory factors for the occurrence of complacency within shipboard engineering teams, as argued by Bielić et al. [24]. Leadership complacency is one of the complacency categories, and it develops due to the leader's poor communication skills and inadequate leadership style. Kim and Gausdal [25] identified coaching, role modeling, pressure, consultation, and exchange tactics as the five core tactics of shipboard leaders to influence subordinates safety compliance and participation behaviors in shipboard operations. Their research indicated that more relationship-oriented leaders are more effective in influencing their subordinates' safety behaviors.

It is of the utmost importance that those seafarers assigned emergency duties during a crisis, such as abandoning ship, can effectively communicate and work as a team to perform their duties as safely as possible [26,27]. Seafarers' experience, engagement, and adequate understanding of their duties are among the most critical factors for making the right decisions during a crisis. A high safety level onboard a ship cannot be attained without instilling effective teamwork [26,27]. It is a basis for success in a crisis, and is one of the critical characteristics of safety. Another aspect of safety leadership is sustainability because adequate leadership leads to fewer accidents, prevents marine pollution and injuries, and positively affects the economic point of view.

In addition to safety and environmental protection, effective safety management has a positive economic effect on the company's operations. It positively affects the employees' 
safety behavior and attitudes toward safety, thus preventing injuries and lost time due to injuries while increasing productivity. Higher productivity and the protection of human lives and the environment complement each other. Therefore, companies with higher safety standards usually manage their businesses very well [28-30].

It can be concluded that leadership style might affect the safety of persons and their wellbeing, the safety of the ship, the protection of the environment, and company business. Because it is commonly accepted that sustainability can be represented with three pillars (social, economic, and environmental) [31], it can be argued that an adequately implemented leadership style might have a positive effect on all three pillars, as presented in Table 1.

Table 1. Effect of safety leadership on sustainability elements.

\begin{tabular}{cc}
\hline Sustainability Element & Effective Safety Leadership \\
\hline Social & $\begin{array}{c}\text { Improved safety of persons at sea } \\
\text { Improved working conditions }\end{array}$ \\
Economic & $\begin{array}{c}\text { No cost incurred from incidents/accidents } \\
\text { Protection of property } \\
\text { The company's reputation is high due to the low number of } \\
\text { incidents/accidents }\end{array}$ \\
\hline Environmental & Less environmental pollution resulting from \\
incident/accidents
\end{tabular}

Pantouvakis and Vlachos, in [32], examined the effect of leadership on sustainable performance in shipping. Their study found that different leadership styles affect sustainable performance differently, but they all affect it to varying degrees. According to the authors, sustainability must be included in all companies' values equations [32]. Galpin and Whittington, in [33], developed a sustainability leadership model where the model's core is an engaged workforce. Leaders are the driving force for the followers' motivation, and they are the ones to motivate the workforce to move beyond borders and achieve the sustainability goals set by the company [33]. According to [34], one of the factors that play a vital role in moving toward sustainability is leadership style. It plays a vital role in adopting set sustainability goals and ensuring that sustainability goals are incorporated into tasks.

Following the challenges that safety leadership has onboard ships, this paper aims to determine the application of those safety leadership characteristics and skills essential for shipboard officers sailing on merchant ships, and investigate whether junior and senior officers have different perspectives on those characteristics and skills. The research hypothesis is formulated as follows: "Effective safety leadership style onboard ships as perceived by seafarers consists of latent components being elements of transformational and transactional leadership styles."

\section{Leadership Styles}

According to Cooper, there are two types of leaders: positional and inspirational [30]. Positional leaders lead based on the power assigned to them because of their position within the management structure. Their leadership is based on issuing instructions and orders that need to be executed. Persons who are ranked lower in the hierarchical chain must obey them because of the chain of command. Unlike positional ones, inspirational leaders inspire people with their passion and enthusiasm for their goals [30,35]. Leaders regularly select one of three dominant leadership styles: (1) transformational, (2) transactional, and (3) servant [30].

Those leaders that lead by employing transformational leadership style shape and transform the company culture toward the set goal, and do everything to achieve it. They try to merge the sense of identity of their followers with the vision of the company, to provide the possibility for improvement by promoting self-confidence among their fol- 
lowers. By challenging and examining the prevailing assumptions, they constantly seek to drive change and move followers beyond their limits [30]. According to Bass [36], transformational leadership consists of the leader's four behaviors: idealized influence, inspirational motivation, intellectual stimulation, and individualized consideration. Idealized influence occurs when a leader sets and exhibits high moral behavioral standards, and becomes a role model for subordinates based on trust. Followers admire, respect, and trust such leaders, identify with them and mimic them. Such a leader meets his followers needs rather than his own, and achieves even greater trust and loyalty. He is consistent in behaving according to ethical principles and moral values. Leaders that apply inspirational motivation challenge their subordinates to ignore their personal goals and submit to the collective goals, which are achieved by clarity of communication and visualizing a positive image of the collective after fulfilling the set goal. Leaders motivate their followers by providing meaning and challenge to their work. In this way, individual and team spirit is aroused, and at the same time, optimism and enthusiasm for work are exhibited. Leading through intellectual stimulation involves encouraging followers to share their views on problems, communicate about set standards, and think creatively. This leader encourages followers to be innovative and creative, and wrong conclusions are not condemned or ridiculed. New problem-solving ideas are obtained from followers that are involved in the decision-making process. In this way, the leader can get different views of problems, and different solutions, and decide based on obtained, communicated views and opinions. Recognizing the unique needs and abilities of followers is a quality of leadership by applying individualized consideration. The leader acts as a mentor and pays attention to the needs of individuals for achievement and growth. He develops new opportunities to acquire new knowledge and teach his followers. The leader recognizes the individual differences of the followers in terms of their desires and needs. He seeks to teach followers to recognize and apply their full potential by tailoring their approach. Each of these four enumerated dimensions of transformational leadership is applicable in safety leadership [36-41].

Transactional leaders build an organization's culture through reward or punishment for a particular performance. Leaders using a transactional leadership style typically set appropriate safety goals and manage followers' safety performances toward the goal by rewarding appropriate behavior or punishing inappropriate attitudes toward the set goal and desired safety practices. This way of leading implies that followers have accepted following the leader and his goals in exchange for praise, rewards, or the avoidance of punishment. Praises and awards are intended for subordinates who perform their tasks following the set goals. For leadership to be successful, the goals and tasks must be clear, and after the successful completion of the task, individuals are praised, which results in the expected level of performance. During active transactional leadership, the leader sets performance standards and can punish subordinates that do not comply with them. In the active transactional leadership style, the leader closely monitors the followers' performance, especially the errors and deviations from set standards and performance methods, and takes corrective actions to return them to the desired path toward the set goal.

In contrast to transformational leadership, transactional leadership is based on nonindividualized, strictly hierarchical relationships, and usually encompasses three leadership dimensions: constructive leadership, corrective leadership, and laissez-faire leadership. In constructive leadership, followers are offered material rewards such as a raise in salary or a promotion to ensure the desired performance. Clear communication between the leader and followers is key to understanding individual needs and opportunities and offering the desired motivational rewards. In corrective leadership, the leader monitors and compares the individual's performance with the set standards, thus detecting possible errors and ordering their correction. In laissez-faire (passive) leadership, the leader does not, as a rule, control the performance of the followers, and only in exceptional cases (emergency) orders and manages subordinates' performance [30,36,37,41-44].

Servant leaders facilitate the followers' task performance, thus maintaining the company's culture and goals as set. They build personal relationships with followers through 
dialog and open communication, support their work, recognize their potential, and ultimately release them, thus leading to the company's goal. In servant leadership, leaders will lead their followers toward success by facilitating their needs. For example, such leaders participate in safety committees, attend safety meetings, support employee ideas to improve safety and monitor the implementation of corrective actions to ensure their adequacy and the ultimately desired safety performance [30].

Each of these leadership styles has its application, and none can be characterized as better or worse than the others. The success of achieving the set goals depends on how the leader uses a particular style [45]. For example, if a leader treats followers with respect (and vice versa), is honest with them and develops teamwork, he will effectively influence safety performance [46-48].

\section{Methodology}

The tool used in the research was a survey questionnaire that was developed based on the literature review. The survey questions' goal was to determine the application of important leadership qualities and characteristics on board a ship, and reveal latent components affecting safety leadership. All questions were as neutral as possible to avoid stereotype bias. A pilot survey was prepared before the final survey, to avoid biased responses. The survey was available online via Google forms. Participation in the survey was optional, and anonymity and confidentiality were guaranteed to all respondents, to avoid biased participation. The survey, titled "Importance of leadership qualities onboard vessels" is a part of a research project, aiming to identify the best practices of safety leadership in shipping, and determine desirable leadership qualities and their application on board merchant ships, which began in November 2017.

The survey was composed of 22 questions aiming to provide insight into seafarers' attitudes on safety leadership applied onboard their ships. The first five questions dealt with demographics (rank, ship type, age, years of sea service, and nationality), and the subsequent 17 questions dealt with the seafarers' perceptions of and opinions on safety leadership-related items. The survey questions were of a closed type: demographic questions, multiple-choice questions, simple yes/no questions, and ranking questions (measured on a five-point Likert scale).

A total of 131 seafarers completed the survey. There were seven nationalities represented, where the majority of the respondents were from Croatia $(84.7 \%)$, followed by Turkey $(3.05 \%)$, Ukraine $(1.53 \%)$, Egypt $(0.77 \%)$, Serbia $(0.77 \%)$, Montenegro $(0.77 \%)$ and Bosnia $(0.77 \%)$. In addition, 10 participants left a blank space when asked about their nationality $(7.63 \%)$. The participants' age distribution was as follows: $16 \%$ were younger than 30 years old, $51.9 \%$ were between 31 and 40 years of age, and $32.1 \%$ were older than 41 years of age. A large number of participants $(93.2 \%)$ had served more than five years at sea. More than half of the respondents (55.7\%) declared themselves as masters, chief engineers and senior officers. The remaining $44.3 \%$ were junior officers, electro-technical officers (ETO) and assistant officers. Participants served on oil tankers, liquefied natural gas (LNG) carriers, cruise ships, bulk carriers, container carriers, and other types of ships.

Data collected from the survey were used to gain insight into safety leadership characteristics and skills as perceived by seafarers, and reveal whether there is only one type of leadership present at sea or a combination of different styles. Principal component analysis (PCA) with varimax rotation was applied to the survey data to reduce the number of measured items affecting safety leadership in shipping, and detect the latent factors. PCA analysis was applied on 11 survey questions measured on a five-point Likert scale. The remaining six survey questions were multiple-choice and yes/no questions, and were used to gain additional insight into seafarers' perceptions and opinions on onboard safety leadership, and four questions are used in this paper because they are related to the aims of the study.

For statistical data analysis, the authors used the statistical software $\mathrm{R}$ (version 4.0.0 x64) and RStudio (desktop version 1.3.959.) set of integrated tools designed to utilize R. 


\section{Results}

The Kayser-Meyer-Olkin (KMO) test confirmed that the data was appropriate for the analysis, giving an overall measure of sampling adequacy of 0.72 . Five components resulting from the PCA analysis explained $64.5 \%$ of the total variance (Table 2). They were extracted based on the following analytical criteria: an eigenvalue of more than one and component loading of more than 0.3 .

Table 2. Number of components and explained variance.

\begin{tabular}{ccc}
\hline Component & Variance (\%) & Cumulative Variance (\%) \\
\hline C1 & 17.0 & 17.0 \\
C2 & 15.8 & 32.8 \\
C3 & 12.3 & 45.1 \\
C4 & 11.4 & 56.5 \\
C5 & 8.0 & 64.5 \\
\hline
\end{tabular}

An explanation of latent components derived from PCA analysis is given in Table 3.

Table 3. Extracted latent components affecting safety leadership.

\begin{tabular}{cccc}
\hline Component & Question & Latent Component & Explanation \\
\hline C1 & Q1, Q2 and Q3 & Safety Inspiring [39] & $\begin{array}{c}\text { The leader is a role model of safe behavior and } \\
\text { gives an example to his subordinates }\end{array}$ \\
\hline C2 & Q4 and Q5 & Positive Working Conditions [21] & $\begin{array}{c}\text { The leader encourages cooperation between } \\
\text { shipboard team members and different teams, } \\
\text { and enables working conditions, whereas his } \\
\text { subordinates are feeling comfortable while } \\
\text { performing tasks }\end{array}$ \\
\hline C3 & Q6 and Q7 & Safety Compliance [49,50] & $\begin{array}{c}\text { The leader always complies with safety } \\
\text { regulations and gives extra attention to the } \\
\text { performance of safety training }\end{array}$ \\
\hline C4 & Q8 and Q9 & Crisis Decision -making [51] & $\begin{array}{c}\text { The leader brings essential decisions on his own } \\
\text { in crisis, and other team members' opinions and } \\
\text { suggestions are not expected }\end{array}$ \\
\hline C5 & S10 and Q11 & Safety Participation [21,49,50] & $\begin{array}{c}\text { The leader communicates with team members } \\
\text { on safety-related issues and induces positive } \\
\text { safety behavior in his subordinates }\end{array}$ \\
\hline
\end{tabular}

Survey questions and extracted components with their loadings are presented in Table 4. Loadings in bold indicate the component on which the question is placed.

Table 4. Survey questions and component loadings.

\begin{tabular}{|c|c|c|c|c|c|c|}
\hline No & Question & $\mathrm{C} 1$ & $\mathrm{C} 2$ & $\mathrm{C} 3$ & $\mathrm{C} 4$ & C5 \\
\hline Q1 & $\begin{array}{l}\text { Do you agree that leaders should promote safety, } \\
\text { encourage safe behavior at all times, and promote } \\
\text { safe thinking and use of risk assessments? }\end{array}$ & 0.914 & 0.118 & 0.136 & -0.135 & \\
\hline Q2 & $\begin{array}{l}\text { Do you agree that assertiveness can improve } \\
\text { teamwork on board a vessel and help create a } \\
\text { better working environment? }\end{array}$ & 0.500 & 0.155 & 0.272 & 0.146 & 0.243 \\
\hline Q3 & $\begin{array}{l}\text { Do you agree that leaders should promote a } \\
\text { positive working environment and be able to } \\
\text { inspire others? }\end{array}$ & 0.681 & 0.190 & 0.183 & -0.179 & 0.516 \\
\hline
\end{tabular}


Table 4. Cont.

\begin{tabular}{|c|c|c|c|c|c|c|}
\hline No & Question & $\mathrm{C} 1$ & $\mathrm{C} 2$ & C3 & $\mathrm{C} 4$ & $\mathrm{C} 5$ \\
\hline Q4 & $\begin{array}{l}\text { Are you satisfied with the teamwork onboard } \\
\text { your vessel? }\end{array}$ & 0.184 & 0.813 & 0.116 & & 0.185 \\
\hline Q5 & $\begin{array}{c}\text { Are you satisfied with human relationships } \\
\text { onboard your vessel? }\end{array}$ & & 0.944 & 0.182 & & \\
\hline Q6 & $\begin{array}{l}\text { Do you agree that onboard safety training is } \\
\text { adequately performed? }\end{array}$ & 0.242 & 0.144 & 0.945 & & 0.141 \\
\hline Q7 & $\begin{array}{l}\text { Do you agree that periods of work and rest on } \\
\text { board a vessel are complied with at all times and } \\
\text { truthfully filled in? }\end{array}$ & 0.225 & 0.264 & 0.407 & 0.114 & \\
\hline Q8 & $\begin{array}{c}\text { Do you agree that leaders should bring } \\
\text { important decisions independently without } \\
\text { hearing other team members' opinions and being } \\
\text { a strong authority? }\end{array}$ & & & & 0.997 & \\
\hline Q9 & $\begin{array}{l}\text { Do you agree that a leader should promote a } \\
\text { strict hierarchy and depend on himself when } \\
\text { making crucial decisions in crises? }\end{array}$ & -0.120 & & 0.220 & 0.351 & 0.175 \\
\hline Q10 & $\begin{array}{l}\text { Do you agree that all ship's team members } \\
\text { should participate in decision-making and } \\
\text { express their opinion without fear? }\end{array}$ & 0.351 & & 0.264 & -0.114 & 0.371 \\
\hline Q11 & $\begin{array}{l}\text { Do you agree that a leader should provide } \\
\text { guidance and let his subordinates perform their } \\
\text { work without supervision and pressure? }\end{array}$ & 0.178 & 0.122 & & 0.178 & 0.568 \\
\hline
\end{tabular}

Components $\mathrm{C} 1, \mathrm{C} 2$, and $\mathrm{C} 5$, presented in Table 3, can be considered transformational leadership style elements, while C 3 and C4 can be considered transactional style elements. Therefore, the composite means of extracted components were calculated and are presented in Table 5. Composite means were also calculated separately for masters, chief engineers and senior officers (group 1), and junior officers, ETOs and assistant officers (group 2).

Table 5. Composite means of the extracted components.

\begin{tabular}{ccccc}
\hline Component & Question & Group 1 Composite Mean & Group 2 Composite Mean & Total Composite Mean \\
\hline C1 & Q1, Q2 and Q3 & 1.87 & 1.96 & 1.91 \\
C2 & Q4 and Q5 & 2.48 & 2.39 & 2.44 \\
C3 & Q6 and Q7 & 2.71 & 2.71 & 2.71 \\
C4 & Q8 and Q9 & 3.24 & 3.32 & 3.26 \\
C5 & Q10 and Q11 & 2.23 & 2.13 & 2.19 \\
\hline
\end{tabular}

Q4 and Q5: 1 = very satisfied; 2 = satisfied; 3 = neutral; 4 = dissatisfied; 5 = very dissatisfied; Q1 through Q3 and Q6 through Q11: $1=$ strongly agree; 2 = agree; $3=$ neutral; 4 = disagree; $5=$ strongly disagree.

The group 2 composite mean values of extracted components were somewhat higher than the composite mean calculated for group 2 for $\mathrm{C} 1$ and C4 (Table 5). Thus, it can be concluded that junior officers, ETOs and assistant officers are, to a small extent, less satisfied with safety inspiration and crisis decision-making than are masters, chief engineers, and senior officers.

The analysis of the remaining four questions showed respondents' opinions on leadership characteristics onboard ships. For example, question 12 (Q12) was: "In your opinion, what is the main reason for the creation of hierarchy/autocratic leadership?" According to them, company pressure is the main reason for the creation of autocratic leadership (35.2\% respondents), followed by the fear of losing authority $(28.8 \%)$ and stereotypical thinking $(24.8 \%)$. 
Question 13 (Q13) was: “Have you ever been directly blamed by your superior for some mistake that you have done unintentionally?" Almost half of the seafarers (48.9\%) reported that their superiors blamed them for unintentional mistakes (blame culture) instead of trying to find a reason why the specific mistake occurred (Q13).

Question 14 (Q14) was: "Have you experienced a situation where your superior officer did not explain to you what he expects from you and what are your tasks?" Again, most of the surveyed seafarers $(76.2 \%)$ declared that their superiors did not explain their jobs, nor did they explain to them what was expected of them.

In question 15 (Q15), seafarers were asked: "In your opinion, which are the three most important leadership qualities in crises? (abandon vessel, evacuation, fire, oil spill, etc.)." Knowledge was rated as the most desirable and important leadership quality ( $85.5 \%$ of the respondents), communication was the second $(81.7 \%)$, and confidence was the third $(63.4 \%)$.

\section{Discussion}

Safety leadership can be observed as a mixture of transactional and transformational leadership styles, where a leader should be experienced and knowledgeable enough to apply an adequate style at any given moment. That means that leaders should be able to estimate which style to apply according to the situation. Of course, whether they will be able to do that or not depends on their knowledge and experience, but it should be noted that experience without knowledge, in some cases, is useless, particularly in the case of positional leaders who are afraid for their position and status.

More than one-third of respondents believe that company pressure has a negative effect on shipboard leadership, and creates a steep traditional hierarchy that is not desirable on ships (Q12). Leaders with low self-confidence and knowledge believe that a strong hierarchy onboard a ship will protect their position, and hide "behind" it. In such a leadership style, the goals set and the tasks that are given cannot be questioned by subordinates, and strict compliance and obedience are expected from them. Thus, the leaders feel safe and do not expect their position or authority to be questioned. Stereotypical thinking includes those senior officers who believe that ships cannot sail without strong authority and hierarchy, as was the case a few hundred years ago on the tall ships.

The goal of safety leadership should be discovering the reasons and root causes for near-misses, incidents, and non-conformities, not assigning blame to individuals (Q13), because, in that way, recurrence might be prevented. If the leader tries to find someone to blame and put the guilt on him, instead of finding the root causes of an unwanted event, it might have an undesired negative effect on safety because subordinates will not report such events and will try to cover them up.

Without adequate familiarization with the task and desired outcome, it cannot be expected that the seafarer will be able to complete a given job successfully (Q14). It is worth mentioning the case of an inexperienced cadet who was disembarked from a ship due to severe injuries (second-degree burns). His superior officer was inexperienced, and gave him a dangerous task without adequately supervising and explaining it thoroughly. As a result, the cadet was injured during his job execution and was repatriated after being released from the hospital [52]. A study by Uğurlu et al. [53] confirmed that cadets are a high-risk group of seafarers, and their supervisors should make sure that clear and precise instructions for the job are given, besides adequate familiarization and supervision during the work. Therefore, leaders should pay attention and make sure that their team members are fully aware of the desired task performance and, most importantly, perform it safely. Furthermore, each crewmember must be familiarized with his duties onboard a ship, and before starting any task, a meeting should be held to clarify possible uncertainties.

According to the respondents, knowledgeable leaders are desirable in emergencies (Q15). Subordinates have strong confidence in such leaders and believe that they can find solutions to resolve the crisis. In addition, communication is the following desirable characteristic. The leader should clearly communicate the subordinates' tasks and expected 
results in crisis, making team members useful and not keeping them in the dark. On the other hand, if the leader is unconfident, crewmembers might act in isolation during a crisis, and negatively affect safety and environmental protection.

The research resulted in five latent components of safety leadership, being elements of transformational and transactional leadership styles. Safety-inspiring subordinates, inducing favorable working conditions, compliance with safety regulations and procedures, crisis decision-making (preferably including other team members), and safety participation are recognized as latent components affecting safety leadership onboard ships. Since safety leadership affects sustainability in shipping, it can be concluded that these latent components impact adopting sustainability in shipping. Furthermore, it was shown that both transformational and transactional leadership styles, if adequately applied, might improve safety onboard a ship and positively affect sustainability elements. Therefore, further research on each latent component might give valuable insight into the development of sustainability in the maritime industry through effective and adequate leadership, while further research on leadership styles aiming to specify each leadership style's effect might be beneficial.

In a practical sense, according to the survey results, five latent components represent desirable characteristics that the shipboard leader needs to adapt to manage shipboard operations safely and sustainably. Shipboard leaders and shipping industry stakeholders should be aware of these desirable safety leadership characteristics and instill them during education for new seafarers, and through shipboard and shore-based training for active seafarers. Good shipboard safety leadership is a prerequisite for effective and safe operations, and its positive characteristics must be instilled within all shipboard command structures. Besides sustainability, leadership style directly affects the safety culture onboard a ship, and thus the safety behavior of crewmembers. To create a working environment where crewmembers work in teams, and cooperate and comply with safety rules and procedures, a leader needs to reject the traditional shipboard hierarchy to some extent (not merely giving orders and managing people as assets) and become more relationship-oriented. Officers onboard ships should be aware that good teamwork and human relations are pillars of shipboard safety, and that they are the ones to create a climate that will brace the safety culture at sea, and increase safety and protect the marine environment.

Seafarers perceive the successful leader as a knowledgeable, communicative and confident person, taking care of their subordinates and creating a positive working environment onboard a ship. An effective leader creates teamwork, provides guidance for crewmembers, and acts as a role model whom crewmembers emulate. The leader should encourage his subordinates' participation when bringing decisions, but during emergencies, when there is no time for discussion, he must have adequate knowledge and competence to act in the best way and resolve the situation. The leader should communicate his decisions to his team members at all times, allowing for their input and suggestions.

The seafarers' opinion that company pressure, fear of losing authority, and stereotypical thinking are reasons for autocratic leadership development is an important finding. It can be argued that in crises where quick decision-making is imperative, autocratic leadership could be beneficial (considering that the leader has excellent knowledge and experience), although it is not a generally desirable leadership style onboard a ship. According to the survey results, the company's human resources department should be well aware of this fact and implement more desirable and relationship-oriented leadership styles, which are more appealing to seafarers.

The research results gave valuable insight into desirable safety leadership characteristics that could be applied in the marine industry. In addition, experienced seafarers' opinions on leadership issues gave important input in addressing safety and environmental protection at sea. 


\section{Conclusions}

The IMO works diligently to develop model courses, aiming to assist training institutions and their teachers and course instructors in knowledge transfer and organizing courses for seafarers. IMO model courses are a tool developed to instill adequate leadership styles onboard ships and help to improve safety and environment protection. IMO has developed several model courses, such as IMO Model Course 1.39 Leadership and Teamwork, which is designed to meet the STCW requirements for applying leadership and teamwork skills, in line with the 2010 Manila Amendments; and IMO Model Course 1.40 Use of Leadership and Managerial Skills, designed to enable seafarers at the management level to meet the mandatory minimum standards of competence in the use of leadership and managerial skills, as specified in the STCW Convention. In addition, it is worth mentioning the IMO Model Courses 1.41 Passenger Ship Crowd Management Training and 1.41 Passenger Ship Crisis Management and Human Behavior Training, which are designed especially for passenger ships. Shipping companies' shore-based management should introduce adequate leadership strategies, human relations, and teamwork on all shipboard hierarchy structures, and implement it via the safety management system (SMS).

Crewmembers' safety and environmental protection are directly related to their understanding of given tasks and adequate job planning before execution. However, seafarers reported that their superiors did not adequately explain the given task, and thus unsafe conditions might arise. Therefore, planning and adequately communicating the details of jobs onboard the ship is an essential element of safety leadership, and crewmembers should instantly provide feedback to their superiors if there are any uncertainties about the given job.

Furthermore, many respondents reported that their superiors blamed them for unintentional mistakes made during the execution of a given job. Blame culture is undesirable on board ships, as it creates fear and distrust, thus undermining good teamwork and healthy human relationships. Hence, shipboard leadership must introduce a just culture, a concept opposite to blame culture, where the aim is not to find someone to blame but to discover root causes, and implement adequate corrective measures and prevent a recurrence.

The limitation of the presented research is a relatively low sample size, although participants' sea time experience could be considered an added value factor for the overall reliability of results. Another significant limitation is a relatively large number of a single nationality in participants in the survey sample because it might result in biased answers. Furthermore, because all survey participants were officers, the research did not include lower-ranking crew members' perspectives on leadership characteristics and skills. In addition, it should be pointed out that there might be differences in leadership characteristics between seafarers serving on different types of ships. For example, it would be interesting to see whether there are differences between seafarers' perceptions of leadership characteristics on cruise ships and cargo ships.

Future research that will include a much larger sample size with a more diverse nationality composition, allowing better data adequacy and more accurate conclusions, could be seen as a proper answer to the mentioned limitation of the research done. In addition, future research should include seafarers of all ranks (not just officers) to get a more accurate view of the characteristics and skills that shipboard leaders need to possess. Finally, a larger sample size will certainly divide seafarers according to ship type (cruise and cargo) and provide an analysis of whether some differences in perceptions on leadership exist.

Author Contributions: Conceptualization, N.H., V.F. and S.V.; methodology, N.H. and M.M.; software, N.H. and M.M.; validation, N.H., V.F. and S.V.; formal analysis, N.H.; investigation, N.H. and S.V.; resources, N.H. and S.V.; data curation, N.H.; writing-original draft preparation, N.H.; writing-review and editing, V.F. and S.V.; visualization, N.H.; supervision, V.F and S.V. All authors have read and agreed to the published version of the manuscript.

Funding: This research received no external funding. 
Institutional Review Board Statement: The study was conducted according to the guidelines of the Declaration of Helsinki, and approved by the Ethics Committee of the University of Dubrovnik (Ethics approval no. 835/21, 19 November 2020).

Informed Consent Statement: Informed consent was obtained from all subjects involved in the study.

Data Availability Statement: Data are available from the corresponding author on request.

Acknowledgments: The authors would like to thank all the seafarers who participated in the survey.

Conflicts of Interest: The authors declare no conflict of interest.

\section{References}

1. Slišković, A.; Penezić, Z. Occupational stressors, risks and health in the seafaring population. Rev. Psychol. 2015, 22, 29-39. [CrossRef]

2. Kim, T.; Sydnes, A.K.; Batalden, B.-M. Development and validation of a safety leadership Self-Efficacy Scale (SLSES) in maritime context. Saf. Sci. 2021, 134, 1-11. [CrossRef]

3. Bielić, T.; Ivanišević, D.; Gundić, A. Participation-Based Model of Ship Crew Management. Promet Traffic Transp. 2014, 26, 437-443. [CrossRef]

4. Vujičić, S.; Hasanspahić, N.; Mišković, D. Importance of Leadership Qualities on Board Ships with Emphasis on Crisis Situations; ATINER'S Conference Paper Series, No: TRA2018-2529; Athens Institute for Education and Research: Athens, Greece, 2018.

5. Theotokas, I.; Lagoudis, I.N.; Kotsiopoulos, N. Leadership Profiling of Ocean Going Ship Masters. Asian J. Shipp. Logist. 2014, 30, 321-343. [CrossRef]

6. Hanzu-Pazara, R.; Popescu, C.; Varsami, A. The role of teamwork and leadership skills for the safety of navigation. In The 13th Annual General Assembly of the IAMU, Expanding Frontiers-Challenges and Opportunities in Maritime Education and Training, Proceedings of the AGA 13, St. John's, NL, Canada, 15-17 October 2012; International Association of Maritime Universities: St. John's, NL, Canada, 2012; pp. 317-326.

7. Senders, J.W.; Moray, N.P. Human Error: Cause, Prediction, and Reduction; Lawrence Erlbaum Associates: Hillsdale, NJ, USA, 1991.

8. Bielić, T.; Hasanspahić, N.; Čulin, J. Preventing marine accidents caused by technology-induced human error. Sci. J. Marit. Res. 2017, 31, 33-37.

9. Madonna, M.; Monica, L.; Anastasi, S.; Di Nardo, M. Evolution of Cognitive Demand in the Human-Machine Interaction Integrated with Industry 4.0 Technologies. Wit Trans. Built Environ. 2019, 189, 13-19. [CrossRef]

10. Di Nardo, M.; Gallo, M.; Madonna, M.; Santillo, L.C. A Conceptual Model of Human Behaviour in Socio-technical Systems. In Intelligent Software Methodologies, Tools and Techniques, Proceedings of the 14th International Conference, SoMeT 2015, Naples, Italy, 15-17 September 2015; Fujita, H., Guizzi, G., Eds.; Springer International Publishing: Cham, Switzerland, 2015.

11. Marine Accident Investigation Branch (MAIB) - GOV.UK. Report on the Investigation of the Grounding of Ovit in the Dover Strait on 18 September 2013. 2014. Available online: https:/ / assets.publishing.service.gov.uk/media/547c6f2640f0b60244000007 /OvitReport.pdf (accessed on 15 January 2021).

12. Marine Accident Investigation Branch (MAIB)_GOV.UK. Report on the Investigation of the Fire on Board Celtic Carrier 24 Miles West of Cape Trafalgar, Spain on 26 April 2013. 2014. Available online: https://assets.publishing.service.gov.uk/media/547c6f3 4ed915d4c0d00001b/Celtic_Carrier.pdf (accessed on 15 January 2021).

13. Ministry of Infrastructures and Transports. Marine Casualties Investigative Body. Cruise Ship Costa Concordia. Report on Safety Technical Investigation. Available online: https:/ / www.mitma.gob.es/recursos_mfom/2012costaconcordia.pdf (accessed on 20 January 2021).

14. Avio, C.G.; Cardelli, L.R.; Gorbi, S.; Pellegrini, D.; Regoli, F. Microplastics pollution after the removal of the Costa Concordia wreck: First evidences from a biomonitoring case study. Environ. Pollut. 2017, 227, 207-2014. [CrossRef]

15. Schröder-Hinrichs, J.-U.; Hollnagel, E.; Baldauf, M. From Titanic to Costa Concordia-A century of lessons not learned. WMU J. Marit. Aff. 2012, 11, 151-167. [CrossRef]

16. Giustiniano, L.; Pina e Cunha, M.; Clegg, S. The dark side of organizational improvisation: Lessons from the sinking of Costa Concordia. Bus. Horiz. 2016, 59, 223-232. [CrossRef]

17. Mitsui, O.S.K. Lines (MOL). Available online: https://www.mol.co.jp/en/pr/2020/20090.html (accessed on 20 January 2021).

18. International Maritime Organization (IMO). Final Act of the Conference of Parties to the International Convention on Standards of Training, Certification and Watchkeeping for Seafarers (STCW), 1978; International Maritime Organization: Manila, Philippines, 2010.

19. International Maritime Organization (IMO). Model Course 1.39, Leadership and Teamwork; International Maritime Organization: London, UK, 2014.

20. $\mathrm{Wu}, \mathrm{T} . \mathrm{C} . ;$ Chen, C.H.; Li, C.C. Correlation among safety leadership, safety climate and safety performance. J. Loss Prevent. Proc. 2007, 6, 261-272. [CrossRef]

21. Griffin, M.A.; Talati, Z. Safety Leadership; Oxford Handbooks online 2014; Oxford University Press: New York, NY, USA, 2014. [CrossRef]

22. Lu, C.-S.; Yang, C.-S. Safety leadership and safety behavior in container terminal operations. Saf. Sci. 2010, 48, 123-134. [CrossRef] 
23. Bhattacharya, S.; Tang, L. Middle managers' role in safeguarding OHS: The case of the shipping industry. Saf. Sci. 2013, 51, 63-68. [CrossRef]

24. Bielić, T.; Čulin, J.; Poljak, I.; Orović, J. Causes of and Preventive Measures for Complacency as Viewed by Officers in Charge of the Engineering Watch. J. Mar. Sci. Eng. 2020, 8, 517. [CrossRef]

25. Kim, T.; Gausdal, A.H. Leaders' Influence Tactics for Safety: An Exploratory Study in the Maritime Context. Safety 2020, 6, 8. [CrossRef]

26. Vukonić, D.; Bielić, T.; Russo, A. Organizational factors in management of "Mega Cruise Ships" from Crowd Management Control aspect. Sci. J. Marit. Res. 2016, 30, 58-66. [CrossRef]

27. Hetherington, C.; Flin, R.; Mearns, K. Safety in shipping: The human element. J. Saf. Res. 2006, 37, 401-411. [CrossRef] [PubMed]

28. Veltri, A.; Pagell, M.; Behm, M.; Das, A. A Data-Based Evaluation of the Relationship between Occupational Safety and Operating Performance. J. SHEE Res. 2007, 4, 1-22.

29. Fernández-Muñiz, B.; Montes-Peón, J.M.; Vázquez-Ordás, C.J. Relation between occupational safety management and firm performance. Saf. Sci. 2009, 47, 980-991. [CrossRef]

30. Cooper, D. Effective Safety Leadership. Understanding Types \& Styles That Improve Safety Performance. Prof. Saf. 2015, 60, 49-53.

31. Purvis, B.; Mao, Y.; Robinson, D. Three pillars of sustainability: In search of conceptual origins. Sustain. Sci. 2019, 14, 681-695. [CrossRef]

32. Pantouvakis, A.; Vlachos, I. Talent and leadership effects on sustainable performance in the maritime industry. Transp. Res. Part D 2020, 86, 102440. [CrossRef]

33. Galpin, T.; Whittington, J.L. Sustainability leadership: From strategy to results. J. Bus. Strategy 2012, 33, 40-48. [CrossRef]

34. Vågfelt, H. Sustainability Transitions in the Shipping Industry-Analyzing Organizational Preferences for Meeting Contextual Challenges. Master's Thesis, Department of Shipping and Marine Technology, Chalmers University of Technology, Gothenburg, Sweden, 2016.

35. Zenger, J.H.; Folkman, J.R.; Edinger, S.K. The Inspiring Leader: Unlocking the Secrets of How Extraordinary Leaders Motivate; McGraw-Hill: New York, NY, USA, 2009; ISBN 978-0071621243.

36. Bass, B.M. Leadership: Good, Better, Best. Organ. Dyn. 1985, 13, 26-40. [CrossRef]

37. Kapp, E.A. The influence of supervisor leadership practices and perceived group safety climate on employee safety performance. Saf. Sci. 2012, 50, 1119-1124. [CrossRef]

38. Hoffmeister, K.; Gibbons, A.M.; Johnson, S.K.; Cigularov, K.P.; Chen, P.Y.; Rosecrance, J.C. The differential effects of transformational leadership facets on employee safety. Saf. Sci. 2014, 62, 68-78. [CrossRef]

39. Pilbeam, C.; Doherty, N.; Davidson, R.; Denyer, D. Safety Leadership Practices for Organizational Safety Compliance: Developing a research agenda from a review of the literature. Saf. Sci. 2016, 86, 110-121. [CrossRef]

40. Avolio, B.J.; Bass, B.M.; Jung, D.I. Re-examining the components of transformational and transactional leadership using the Multifactor Leadership Questionnaire. J. Occup. Organ. Psych. 1999, 72, 441-462. [CrossRef]

41. Bass, B.M.; Avolio, B.J.; Jung, D.I.; Berson, Y. Predicting Unit Performance by Assessing Transformational and Transactional Leadership. J. Appl. Psychol. 2003, 88, 207-218. [CrossRef]

42. Zohar, D. The effects of leadership dimensions, safety climate, and assigned priorities on minor injuries in work groups. J. Organ. Behav. 2002, 23, 75-92. [CrossRef]

43. Zohar, D. Modifying supervisory practices to improve subunit safety: A leadership-based intervention model. J. Appl. Psychol. 2002, 87, 156-163. [CrossRef]

44. Podsakoff, P.M.; Todor, W.D.; Skov, R. Effects of Leader Contigent and Noncontigent Reward and Punishment Behaviors on Subordinate Performance and Satisfaction. Acad. Manag. J. 1982, 25, 810-821.

45. Nixon, P.; Harrington, M.; Parker, D. Leadership performance is significant to project success or failure: A critical analysis. Int. J. Product. Perform. Manag. 2012, 61, 204-216. [CrossRef]

46. Effelsberg, D.; Solga, M.; Gurt, J. Transformational Leadership and Follower's Unethical Behavior for the Benefit of the Company: A Two-Study Investigation. J. Bus. Ethics 2014, 120, 81-93. [CrossRef]

47. Müller, R.; Turner, R. Leadership competency profiles of successful project managers. Int. J. Proj. Manag. 2010, 28, 437-448. [CrossRef]

48. Yang, L.-R.; Huang, C.-F.; Wu, K.-S. The association among project manager's leadership style, teamwork and project success. Int. J. Proj. Manag. 2011, 29, 258-267. [CrossRef]

49. Mullen, J.E.; Kelloway, E.K. Safety leadership: A longitudinal study of the effects of transformational leadership on safety outcomes. J. Occup. Organ. Psych. 2009, 82, 253-272. [CrossRef]

50. Clarke, S. Safety leadership: A meta-analytic review of transformational and transactional leadership styles as antecedents of safety behaviours. J. Occup. Organ. Psych. 2013, 86, 22-49. [CrossRef]

51. Alkharabsheh, A.; Ahmad, Z.A.; Kharabsheh, A. Characteristics of Crisis and Decision Making Styles: The Mediating Role of Leadership Styles. Procedia Soc. Behav. Sci. 2014, 129, 282-288. [CrossRef] 
52. Safety4sea. Lack of Experience Leads to Injury Onboard. Available online: https://safety4sea.com/lack-of-experience-leads-toinjury-onboard/ (accessed on 1 July 2021).

53. Uğurlu, Ö.; Kum, S.; Aydogdu, Y.V. Analysis of occupational accidents encountered by deck cadets in maritime transportation. Marit. Policy Manag. 2017, 44, 304-322. [CrossRef] 